\title{
Características produtivas e nutricionais do pasto em sistema agrossilvipastoril, conforme a distância das árvores
}

\author{
Domingos Sávio Campos Paciullo(1), Carlos Augusto Miranda Gomide(1), Carlos Renato Tavares de Castro(1), \\ Priscila Beligoli Fernandes ${ }^{(2)}$, Marcelo Dias Müller ${ }^{(1)}$, Maria de Fátima Ávila Pires ${ }^{(1)}$, \\ Elizabeth Nogueira Fernandes ${ }^{(1)}$ e Deise Ferreira Xavier ${ }^{(1)}$
}

\begin{abstract}
(1)Embrapa Gado de Leite, Rua Eugênio do Nascimento, no 610, Dom Bosco, CEP 36038-330 Juiz de Fora, MG. E-mail: domingos@cnpgl.embrapa.br, cagomide@cnpgl.embrapa.br, castro@cnpgl.embrapa.br muller@cnpgl.embrapa.br, fatinha@cnpgl.embrapa.br, dfxavier@cnpgl.embrapa.br, nogueira@cnpgl.embapa.br (2)Universidade Federal Rural do Rio de Janeiro, Instituto de Agronomia, Departamento de Solos, Rodovia BR 465, Km 07, CEP 23851-970 Seropédica, RJ. E-mail: pri_beli@hotmail.com
\end{abstract}

Resumo - Os objetivos deste trabalho foram avaliar os efeitos de árvores dispostas em renques sobre as características produtivas e nutricionais de Urochloa decumbens e identificar a distância média, na qual ocorre o melhor aproveitamento do sombreamento moderado, em um sistema agrossilvipastoril. Os tratamentos consistiram em distâncias dos pontos de observação ao renque das árvores $(0,3,6,9,12$ e 15 m) e foram distribuídos em blocos ao acaso, com quatro repetições. A densidade de perfilhos e a massa e a taxa de acúmulo de forragem e a composição química do pasto foram avaliadas. A densidade de perfilhos, a massa e a taxa de acúmulo de forragem aumentaram com a distância do renque, com valores máximos de 392 perfilhos $\mathrm{m}^{-2}$, $1.347 \mathrm{~kg} \mathrm{ha}^{-1}$ e $30,1 \mathrm{~kg} \mathrm{ha}^{-1}$ por dia, respectivamente, a 9,1, 10,4 e 8,8 m de distância. Os teores de fibra em detergente neutro não variaram com a distância, enquanto os de fibra em detergente ácido e os de lignina variaram, mas sem um padrão definido de resposta. Os teores de proteína bruta diminuíram quadraticamente com a distância do renque e apresentaram valor máximo sob a copa das árvores $(9,8 \%)$ e mínimo a $13,5 \mathrm{~m}$ de distância (6,5\%). A região entre 7 e $10 \mathrm{~m}$ de distância do renque apresentou maior benefício da sombra moderada sobre as características do pasto.

Termos para indexação: Brachiaria decumbens, Urochloa decumbens, fibra em detergente neutro, massa de forragem, perfilhamento, proteína bruta, sombreamento.

\section{Productive and nutritional traits of pasture in an agrosilvopastoral system, according to the distance from trees}

\begin{abstract}
The objectives of this work were to evaluate the effects of trees arranged in rows on yield and nutritional characteristics of Urochloa decumbens and to identify the average distance in which there is a better use of moderate shading in an agrisilvipasture system. The treatments consisted of distances from measure points to tree rows $(0,3,6,9,12$ and $15 \mathrm{~m})$ and were distributed in randomized blocks, with four replicates. The tiller density, forage mass, forage accumulation rate and chemical composition of pasture were evaluated. The tiller density, forage mass and rates of forage accumulation increased with the distance from tree rows, reaching the highest values of 392 tillers $\mathrm{m}^{-2}, 1,347 \mathrm{~kg} \mathrm{ha}^{-1}$ and $30.1 \mathrm{~kg} \mathrm{ha}^{-1}$ per day, respectively, at 9.1, 10.4 and $8.8 \mathrm{~m}$ of distance. The contents of the neutral detergent fiber did not vary with distance, while the acid detergent fiber and lignin content varied, but without a clear pattern of response. The crude protein contents reduced quadratically with distance from tree rows and had the highest values under trees $(9.8 \%)$ and the lowest at $13.5 \mathrm{~m}$ of distance $(6.5 \%)$. The site of pasture, between 7 and $10 \mathrm{~m}$ of distance from the tree rows showed the highest benefits of moderate shading on pasture traits.
\end{abstract}

Index terms: Brachiaria decumbens, Urochloa decumbens, neutral detergent fiber, forage mass, tillering, crude protein, shading.

\section{Introdução}

O modelo de integração lavoura-pecuária-floresta, conhecido como sistema agrossilvipastoril, constitui uma prática agroflorestal planejada, para se obter benefícios das interações biológicas entre os componentes do sistema. Além disso, o modelo pode possibilitar o aumento de renda da propriedade, pela exploração econômica de mais de um produto comercializável.

Com o crescimento das árvores, em sistemas agrossilvipastoris, há uma diminuição progressiva da luminosidade disponível para o sub-bosque que influencia a produtividade do pasto. O sombreamento pode comprometer a produção de forragem (Castro et al., 1999; Guenni et al., 2008), mas há evidências

Pesq. agropec. bras., Brasília, v.46, n.10, p.1176-1183, out. 2011 
de seus benefícios sob determinadas condições (Rozados-Lorenzo et al., 2007; Yamamoto et al., 2007; Sousa et al., 2010). Em condições de sombreamento moderado, algumas gramíneas, que apresentam tolerância mediana a esse tipo de ambiente, podem manter sua produção semelhante à do cultivo a sol pleno ou mesmo aumentar, quando estabelecidas em solos pobres em nitrogênio (Castro et al., 1999; Paciullo et al., 2008; Sousa et al., 2010).

O valor nutritivo do pasto também é influenciado pela presença de árvores em sistemas agrossilvipastoris, principalmente em razão de adaptações morfofisiológicas (Allard et al., 1991; Buergler et al., 2006; Baruch \& Guenni, 2007). Em condições de sombreamento moderado, aumentos no teor de nitrogênio na folha podem repercutir em melhorias do teor proteico da forragem (Buergler et al., 2006; Kallenbach et al., 2006; Paciullo et al., 2007; Sousa, 2009). Os resultados são indicatvos de pouca ou nenhuma variação nos teores de fibra e na digestibilidade de forrageiras submetidas ao sombreamento (Lin et al., 2001; Buegler et al., 2006; Kallenbach et al., 2006; Sousa et al., 2010).

Algumas variáveis importantes que influenciam a disponibilidade de luz para o sub-bosque, para obtenção de sombra moderada, são a densidade e a disposição das árvores na área de pastagem (Oliveira et al., 2007; Rozados-Lorenzo et al., 2007). Em sistemas agrossilvipastoris, cujo arranjo espacial envolve a disposição das árvores em linhas ou renques com mais de uma linha, é possível supor que haja influência das árvores sobre o pasto, à medida que este se distancia dos troncos. Embora a influência do componente arbóreo nas características do pasto se concentre principalmente sob as copas das árvores, os efeitos do sombreamento podem alcançar regiões localizadas além da projeção das copas (Dias et al., 2007). O conhecimento desse efeito é importante no planejamento de sistemas agrossilvipastoris, no que se refere ao espaçamento entre faixas de árvores, a fim de se obter o máximo benefício da inclusão de espécies arbóreas em pastagens de gramíneas.

Os objetivos deste trabalho foram avaliar os efeitos de árvores dispostas em renques sobre as características produtivas e nutricionais de Urochloa decumbens (Stapf) R.D. Webster e identificar a distância média, na qual ocorre o melhor aproveitamento do sombreamento moderado, em um sistema agrossilvipastoril.

\section{Material e Métodos}

O trabalho foi realizado no Campo Experimental de Coronel Pacheco, da Embrapa Gado de Leite, no Município de Coronel Pacheco, MG, de abril de 2007 a março de 2009, em um sistema agrossilvipastoril instalado em novembro de 1997, em uma área montanhosa com declividade de aproximadamente $30 \%$, a $21^{\circ} 33^{\prime} 22^{\prime \prime} \mathrm{S}, 43^{\circ} 06^{\prime} 15^{\prime \prime} \mathrm{W}$ e a $410 \mathrm{~m}$ de altitude. O clima da região, conforme a classificação de Köppen, é do tipo Cwa (mesotérmico). A precipitação média mensal é de $60 \mathrm{~mm}$ e a temperatura média do ar de $17^{\circ} \mathrm{C}$, de abril a setembro, e de $230 \mathrm{~mm}$ e $24^{\circ} \mathrm{C}$, de outubro a março. O solo da área experimental é do tipo Latossolo Vermelho-Amarelo distrófico de textura argilosa e relevo ondulado. Os valores das características químicas do solo foram: $\mathrm{pH}$ em água, 4,8; $\mathrm{P}$ disponível (Mehlich-1), 4,7 mg dm${ }^{-3}$; Al, 0,9 $\mathrm{cmol}_{\mathrm{c}} \mathrm{dm}^{-3} ; \mathrm{K}, 0,11 \mathrm{cmol}_{\mathrm{c}} \mathrm{dm}^{-3}$; $\mathrm{Ca}, 0,68 \mathrm{cmol}_{\mathrm{c}} \mathrm{dm}^{-3}$ e $\mathrm{Mg}, 0,27 \mathrm{cmol}_{\mathrm{c}} \mathrm{dm}^{-3}$.

Antes do plantio das espécies arbóreas, aplicaramse, de acordo com análise de solo, $1.000 \mathrm{~kg} \mathrm{ha}^{-1} \mathrm{de}$ calcário dolomítico, $600 \mathrm{~kg} \mathrm{ha}^{-1}$ de fosfato de Araxá, $250 \mathrm{~kg} \mathrm{ha}^{-1}$ de superfosfato simples, $100 \mathrm{~kg} \mathrm{ha}^{-1} \mathrm{de}$ cloreto de potássio e $30 \mathrm{~kg} \mathrm{ha}^{-1}$ de FTE BR-16 (3,5\% de $\mathrm{Zn}, 1,5 \%$ de B, 3,5\% de $\mathrm{Cu}$ e $0,40 \%$ de $\mathrm{Mo}$ ). Para o estabelecimento das árvores, adotou-se o plantio em renques, cada um com quatro linhas, no espaçamento de $3 \times 3 \mathrm{~m}$. As faixas com árvores foram estabelecidas em nível e distanciadas em $30 \mathrm{~m}$ umas das outras, o que totalizou a densidade de 342 árvores por hectare. No momento da introdução das árvores, foi plantado o feijão-guandu (Cajanus cajan) entre as faixas arborizadas, a fim de efetuar sua incorporação ao solo como adubo verde, antes do florescimento das plantas. O componente arbóreo foi constituído pelas leguminosas Acacia mangium, Acacia angustissima e Mimosa artemisiana, além de Eucalyptus grandis. As espécies mais representativas do sistema ( $90 \%$ das árvores), no período de 2007 a 2009, eram E. grandis e A. mangium, que apresentavam, em 2008, diâmetros médios à altura do peito de $25,5 \mathrm{~cm}$ e $20 \mathrm{~cm}$, e alturas médias de $21,7 \mathrm{~m}$ e $14,2 \mathrm{~m}$, respectivamente. O pasto de $U$. decumbens $\mathrm{cv}$. Basilisk foi estabelecido no segundo ano, juntamente com a cultura do milho (Zea mays L.). Após a colheita do milho, iniciou-se o pastejo aos

Pesq. agropec. bras., Brasília, v.46, n.10, p.1176-1183, out. 2011 
22 meses depois do plantio das espécies arbóreas, momento em que as árvores haviam atingido porte suficiente para não serem danificadas pelos animais.

Em setembro de 2001, a área foi dividida em oito piquetes de 0,5 ha. Entre os anos de 2001 e 2003, as pastagens foram utilizadas para o pastejo de vacas não lactantes, conforme descrito por Aroeira et al. (2005). No período de 2003 a 2007, a área foi manejada com novilhas leiteiras em regime de lotação intermitente. Detalhes sobre o manejo do pasto e dos animais estão contidos no trabalho de Paciullo et al. (2009).

Para o presente trabalho, os piquetes sob avaliação foram ocupados por novilhas mestiças a cada 35 dias, a fim de estabelecer o pastejo da gramínea por aproximadamente três dias. Os animais foram utilizados apenas para o rebaixamento da vegetação.

Foi adotado o delineamento de blocos ao acaso, com seis tratamentos e quatro repetições. Os tratamentos consistiram de diferentes distâncias dos pontos de observação da pastagem ao renque de árvores. Foi considerada, para as medições das distâncias, a base dos fustes das árvores da primeira linha do renque limítrofe com a pastagem (distância zero), e medidos $0,3,6,9,12$ e $15 \mathrm{~m}$ desde o renque de árvores até o centro do piquete.

Medidas de radiação fotossinteticamente ativa foram tomadas, em dias de céu límpido, nos meses de julho, agosto e setembro (época seca) e nos meses de novembro, dezembro e janeiro (época chuvosa), de cada ano experimental, em três momentos durante o dia (às 9, 12 e 15h), com auxílio de um ceptômetro, marca Accupar, modelo LP 80, (Decagon, Pullman, WA, EUA). Para cada distância ao renque de árvores e em uma linha paralela, foram tomadas cinco medidas, que constituíram a média de cada tratamento.

A massa de forragem foi estimada a partir de cortes realizados nas condições de pré e pós-pastejo. Quatro amostras foram coletadas em cada parcela, com auxílio de moldura metálica de $0,5 \times 0,5 \mathrm{~m}$, de forma sistematizada, a cada $10 \mathrm{~m}$ ao longo de uma faixa paralela à linha de árvores. As plantas foram cortadas à altura de $5 \mathrm{~cm}$ do solo e, em seguida, levadas ao laboratório para separação das frações verde e morta. $\mathrm{Na}$ fração verde das amostras coletadas antes do pastejo, foi contado o número de perfilhos, para estimar-lhes a densidade populacional. As frações do pasto, obtidas nas condições de pré e pós-pastejo, foram secas separadamente em estufa de ventilação forçada, a $55^{\circ} \mathrm{C}$, por 72 horas, para determinação da massa de matéria seca.

A taxa de acúmulo de matéria seca foi calculada pela diferença entre a quantidade de massa de matéria seca de forragem verde do pré-pastejo e a massa seca de forragem verde residual, estimada no dia seguinte ao pós-pastejo, do ciclo anterior. $\mathrm{O}$ valor dessa diferença foi, então, dividido pelo intervalo de desfolha. A taxa de acúmulo foi avaliada apenas durante a época chuvosa do ano.

Das quatro amostras destinadas à estimativa da massa de forragem, coletadas em cada unidade experimental, foram retiradas alíquotas que depois de misturadas constituíram uma amostra composta por parcela. Nessas amostras, foram determinados os teores de proteína bruta (PB), fibra em detergente neutro (FDN), fibra em detergente ácido (FDA) e lignina, conforme Silva \& Queiroz (2002).

A taxa de acúmulo diário de $\mathrm{PB}$ nos tecidos da planta, avaliada apenas na época chuvosa, foi obtida por meio da multiplicação dos valores médios de taxa de acúmulo de matéria seca pelos teores médios de PB do pasto em cada tratamento.

Os dados foram submetidos à análise de variância e regressão, e o modelo mais adequado foi escolhido com base na significância do efeito da regressão e não significância dos desvios avaliados pelo teste $\mathrm{F}$, a $5 \%$ de probabilidade. Para as variáveis densidade de perfilho, massa de forragem e teores de PB, FDN, FDA e lignina, foram considerados os efeitos de distância ao renque de árvores e época do ano seca ou chuvosa. Para as taxas de acúmulo de forragem e de PB, a análise teve como variável independente apenas a distância ao renque de árvores.

\section{Resultados e Discussão}

A radiação incidente no sub-bosque do sistema agrossilvipastoril variou $(p<0,01)$ em função da interação tratamento x época do ano, ou seja, distância ao renque de árvores x época do ano (Figura 1). Para as épocas seca e chuvosa, o modelo mais adequado foi o quadrático, embora com magnitudes de respostas diferentes. Durante a seca, a máxima radiação incidente (média do dia) foi de $856 \mu \mathrm{mol} \mathrm{m} \mathrm{m}^{-2} \mathrm{~s}^{-1}$, obtida a $14,8 \mathrm{~m}$ da faixa de árvores, enquanto, na época chuvosa, a máxima radiação diária foi de $1.788 \mu \mathrm{mol} \mathrm{m}^{-2} \mathrm{~s}^{-1} \mathrm{a}$ 12,5 $\mathrm{m}$ das árvores. As percentagens de sombreamento, 
estimadas a partir dos valores de radiação nas diferentes distâncias ao renque de árvores, em relação à irradiância a sol pleno (área de pastagem adjacente ao sistema agrossilvipastoril, isenta de sombreamento), revelaram padrão e magnitudes de respostas semelhantes $(\mathrm{p}>0,05)$ para as épocas do ano, motivo pelo qual se ajustou uma única equação para esta variável. Observou-se que, mesmo à distância de $15 \mathrm{~m}$ do renque de árvores, houve atenuação da radiação total incidente, o que ocorreu principalmente durante o início da manhã e final da tarde, conforme a elevação solar, em virtude de os renques de árvores estarem dispostos no sentido norte/sul. A área experimental apresenta declividade acentuada, por isso priorizou-se a implantação dos renques de árvores em nível, para aumentar o controle da erosão superficial. Embora o plantio em nível seja recomendado para áreas declivosas, há maior possibilidade de sombreamento do pasto, quando as características topográficas exigem que o plantio seja realizado no sentido norte/sul. Nesse caso, o nível de sombreamento dependerá do espaçamento entre os renques e da altura das árvores. De acordo com os resultados apresentados na literatura (Castro et al., 1999; Paciullo et al., 2007; Guenni et al., 2008), podem-se considerar como sombreamentos moderados os valores estimados a partir da distância de seis metros ao renque de árvores. As percentagens de sombreamento de 60 e $43 \%$, estimadas sob o dossel arbóreo e a $3 \mathrm{~m}$ de distância deste, respectivamente, são consideradas excessivas para o adequado crescimento das gramíneas do gênero Urochloa (Castro et al., 1999; Dias Filho, 2000; Paciullo et al., 2007).

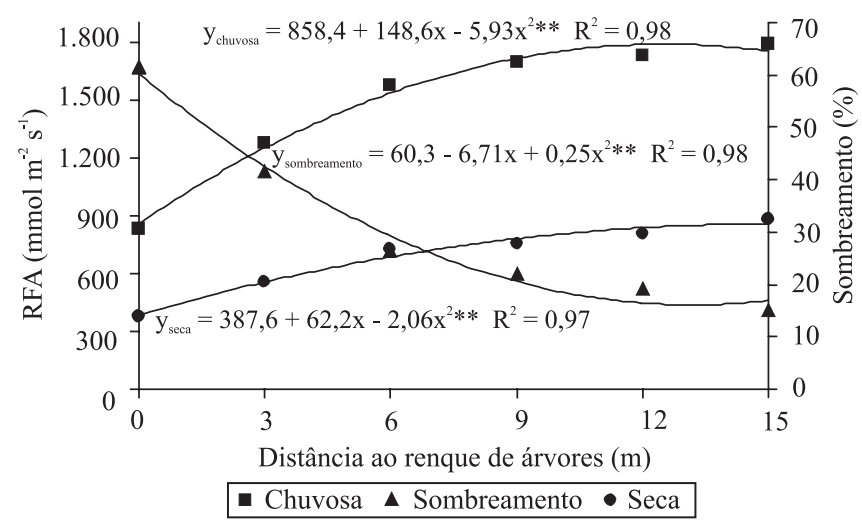

Figura 1. Radiação fotossinteticamente ativa (RFA) nas estações seca e chuvosa e percentagens de sombreamento em sistema agrossilvipastoril, conforme a distância ao renque de árvores.
A densidade de perfilhos variou $(p<0,05)$ com a época do ano e com as distâncias dos renques, mas não com a interação entre esses fatores. Na época chuvosa, a densidade populacional de perfilhos média foi de 450 perfilhos por $\mathrm{m}^{2}$, enquanto, na época seca, verificouse decréscimo da densidade para 258 perfilhos por $\mathrm{m}^{2}$, em função da modificação das condições climáticas inerentes às estações de outono e inverno (época seca), tais como reduções da temperatura do ar, da radiação incidente e da precipitação pluvial. A densidade de perfilhos foi influenciada $(\mathrm{p}<0,05)$, também, pela distância do renque de árvores (Figura $2 \mathrm{~A}$ ), segundo equação quadrática, por meio da qual se estimou número máximo de 392 perfilhos por $\mathrm{m}^{2}$, a 9,1 m de distância das árvores. O sombreamento natural, proporcionado por árvores, altera tanto a intensidade quanto a qualidade da radiação incidente no sub-bosque. A redução da relação vermelho:vermelho distante, em condições de sombreamento natural, apresenta importantes efeitos sobre a morfogênese das plantas, o que diminui, principalmente, o perfilhamento das gramíneas (Gautier et al., 1999; Baruch \& Guenni, 2007). Esse fato, associado à redução da intensidade luminosa, explica a menor densidade de perfilhos observada sob condições de sombra intensa. Por exemplo, a densidade de perfilhos sob a copa das árvores foi $37 \%$ menor que aquela estimada a $9,1 \mathrm{~m}$ de distância do renque de árvores.

As variáveis massa de matéria seca de forragem verde (MSFV), massa de matéria seca de forragem morta (MSFM) e massa de matéria seca de forragem total (MSFT) variaram $(\mathrm{p}<0,05)$, isoladamente, com a época do ano e com a distância do renque de árvores. Na época chuvosa, observou-se maior MSFV (1.497 $\left.\mathrm{kg} \mathrm{ha}^{-1}\right)$ do que na época seca do ano $\left(651 \mathrm{~kg} \mathrm{ha}^{-1}\right)$, mas menores MSFM (383 e $2.417 \mathrm{~kg} \mathrm{ha}^{-1}$ nas épocas chuvosa e seca, respectivamente) e MSFT (1.880 e $3.068 \mathrm{~kg} \mathrm{ha}^{-1}$, nas épocas chuvosa e seca, respectivamente). Os maiores valores de MSFT, observados na época seca, surpreendem, ao considerar-se a escassez dos recursos climáticos disponíveis para o crescimento nessa época. Dois aspectos, ocorridos durante a época seca do ano, devem ser considerados para explicar os resultados alcançados: primeiro, a elevada participação $(78,8 \%)$ de material morto na MSFT do pasto e, segundo, o alto teor de MS da fração verde do pasto (45,3\%). Tanto a elevada participação de material morto, naturalmente com baixas concentrações de umidade, quanto o maior teor de MS do material verde, no período seco do 
ano, comparado ao teor na época chuvosa $(22 \%$, em média), contribuíram para obtenção de elevadas MSFT na época seca.

Em relação às distâncias aos renques, ajustaramse modelos quadráticos às variáveis MSFV, MSFM e MSFT, para as quais se estimaram valores máximos a 10,4, 14,8 e 12,9 m, respectivamente. Assim, a taxa de acúmulo de MS variou de forma quadrática com as distâncias às árvores e atingiu valor máximo de $30,1 \mathrm{~kg} \mathrm{ha}^{-1}$ por dia, à distância de $8,8 \mathrm{~m}$ (Figuras $2 \mathrm{~B}$ e $\mathrm{C}$ ).

O padrão das curvas de resposta das variáveis densidade de perfilhos, taxa de acúmulo e MSFV de MS, em função da distância aos renques (Figuras 2 A, $\mathrm{B}$ e C), foi semelhante ao observado para a radiação incidente no sub-bosque. Essa constatação condiz com a importância da radiação nos processos fotossintéticos dos vegetais, principalmente aqueles de ciclo $\mathrm{C}_{4}$. Níveis de sombreamento acima de $35-40 \%$ podem afetar o crescimento da maioria das gramíneas tropicais (Castro et al., 1999; Baruch \& Guenni, 2007; Paciullo et al., 2007), o que se confirmou neste trabalho, com as menores populações de perfilhos, MSFV e acúmulo de forragem, estimados a até, aproximadamente, $6 \mathrm{~m}$ da faixa de árvores. Embora a $U$. decumbens apresente ajustes morfofisiológicos como estratégia de tolerância ao sombreamento (Guenni et al., 2008; Paciullo et al., 2008), tais mecanismos não foram capazes de compensar a redução de radiação e manter a produtividade do pasto, nas condições de sombreamento intenso a até seis metros do renque de árvores. Os maiores valores para densidade de perfilhos e acúmulo de forragem, estimados a 9,2 e $8,8 \mathrm{~m}$ de distância das árvores, respectivamente, reforçam a capacidade da $U$. decumbens de tolerar a redução moderada da radiação incidente (Castro et al., 1999; Baruch \& Guenni, 2007; Guenni et al., 2008; Paciullo et al., 2008). Outro fato a ser ressaltado diz respeito à dissociação das curvas de resposta da radiação e do acúmulo de forragem a partir de $10 \mathrm{~m}$ de distância do renque de árvores, o que indica que outros fatores, além da radiação, modularam a dinâmica do acúmulo
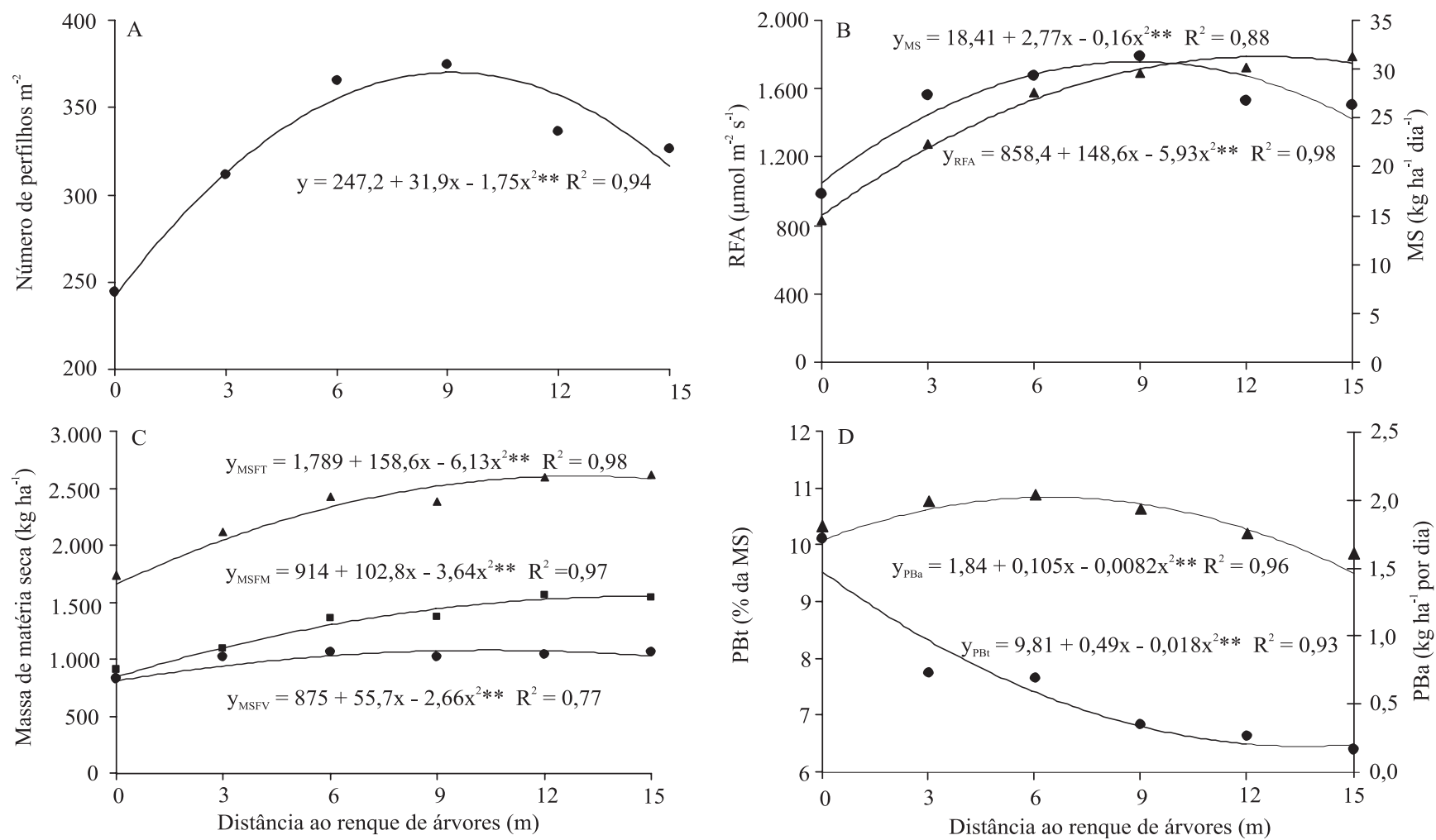

Figura 2. Densidade populacional de perfilhos (A); radiação fotossinteticamente ativa incidente (RFA) e taxa de acúmulo de matéria seca (MS) (B); matéria seca de forragem verde (MSFV), matéria seca de forragem morta (MSFM) e forragem total (MSFT) (C); e acúmulo (PBa) e teores (PBt) de proteína bruta (D), em Urochloa decumbens, em sistema agrosilvipastoril, conforme a distância ao renque de árvores. 
de forragem entre 10 e $15 \mathrm{~m}$ de distância das árvores (Figura $2 \mathrm{~B}$ ).

Os teores de FDN não foram influenciados pelos fatores estudados e alcançaram valor médio de $77,4 \%$. Os teores de FDA e de lignina variaram com a distância, entretanto, as diferenças não apresentaram um padrão definido, o que resultou na ausência de significância $(p>0,05)$ dos modelos linear e quadrático para o ajuste dos dados. Os valores médios de FDA e lignina foram de 45,4 e 6,7\%, respectivamente. Para os teores de lignina, observou-se efeito $(p<0,05)$ de época do ano, com os valores de 6,2 e 7,3\%, estimados para as épocas chuvosa e seca, respectivamente. Pouca ou nenhuma variação, nos teores dos constituintes da parede celular de forrageiras submetidas ao sombreamento, é encontrada na literatura (Lin et al., 2001; Buergler et al., 2006; Kallenbach et al., 2006; Paciullo et al., 2007; Sousa et al., 2010). As variações nos teores de FDN, FDA e lignina parecem estar relacionadas à interação da percentagem de sombra com o estádio de maturidade da planta (Lin et al., 2001; Sousa, 2009). Em condições de elevadas percentagens de sombreamento, as plantas tendem a estiolar com o avanço da maturidade, o que pode resultar em aumentos dos teores de fibra da forrageira. O estiolamento é uma estratégia da planta no qual há o aumento da sua estatura em busca por luminosidade, e esse aumento normalmente ocorre pelo alongamento do colmo. Sousa et al. (2007) atribuíram o aumento no teor de FDA da $U$. brizantha, em resposta ao sombreamento intenso $(74 \%$ da radiação fotossinteticamente ativa plena), ao acentuado estiolamento da planta com o avanço da idade. Esses trabalhos, no entanto, não têm detectado variação nos constituintes da parede celular, ao se compararem as condições de sol pleno e sombreamento moderado (Paciullo et al., 2007; Sousa, 2009), mesmo em condições de idade mais avançada.

Ao contrário dos constituintes da parede celular, os teores de PB variaram de forma consistente com a distância à faixa de árvores (Figura $2 \mathrm{D}$ ). $\mathrm{O}$ valor mínimo foi de 6,5\%, estimado a 13,5 m de distância à faixa de árvores. É interessante observar que o teor de PB foi $51 \%$ maior sob a copa das árvores $(9,8 \%)$ que a $13,5 \mathrm{~m}$ delas $(6,5 \%)$. O efeito positivo do sombreamento nos teores de PB está bem estabelecido na literatura, especialmente em solos com baixos teores de nitrogênio (Wilson, 1998; Paciullo et al., 2007; Sousa et al., 2010), e algumas hipóteses têm sido formuladas para explicar essa relação. Wilson (1996) concluiu que, em condições de sombreamento natural, observamse aumentos da degradação da matéria orgânica e da reciclagem de nitrogênio no solo. Portanto, os maiores teores de PB do pasto, em regiões localizadas mais próximas das árvores, podem estar associados ao maior fluxo de nitrogênio no solo, especialmente porque parte do componente arbóreo era constituído por leguminosas fixadoras de nitrogênio atmosférico. Outro mecanismo que pode ter contribuído para os maiores teores de PB está relacionado ao atraso no desenvolvimento ontogenético de plantas cultivadas à sombra mais intensa. Neste caso, as forrageiras tendem a ser mais jovens fisiologicamente, o que prolonga a fase vegetativa juvenil e permite a manutenção dos níveis metabólicos mais elevados por maior período de tempo, conforme resultados discutidos por Sousa (2009). O aumento do teor de PB, em plantas à sombra, poderia ainda estar associado à redução do tamanho da célula por causa do sombreamento. Kephart \& Buxton (1993) argumentaram que o reduzido tamanho da célula, com a manutenção da quantidade de nitrogênio mais ou menos constante por célula, pode resultar em aumento da concentração de nitrogênio.

$\mathrm{O}$ acúmulo diário de $\mathrm{PB}$ nos tecidos das plantas, estimado apenas na época chuvosa, variou $(p<0,05)$ com a distância do renque de árvores (Figura $2 \mathrm{D}$ ) e alcançou valor máximo de $2,20 \mathrm{~kg} \mathrm{ha}^{-1}$ por dia, a $6,6 \mathrm{~m}$ de distância do renque de árvores. Benefícios da presença de árvores na produção de PB também foram observados por Carvalho et al. (1997) e Sousa (2009), em pastagens de $U$. decumbens, que verificaram aumentos de 26 a $31 \%$ na produção de PB do pasto sombreado, em comparação ao pasto a sol pleno.

As variáveis analisadas, com exceção dos constituintes da parede celular, foram influenciadas pelas árvores segundo um padrão definido de aumento ou redução nos valores, conforme o afastamento do renque de árvores, o que confirmou a hipótese deste trabalho. A influência das árvores alcança posições do terreno que se localizam além da área de projeção de suas copas, como também observado por Dias et al. (2007). Este fato se deve tanto ao efeito do sombreamento, que alcança locais do pasto afastados do componente arbóreo, como à presença de serapilheira das árvores além da projeção de suas copas, verificado por Xavier (2009).

Pesq. agropec. bras., Brasília, v.46, n.10, p.1176-1183, out. 2011 
Uma análise conjunta dos dados apresentados permite deduzir que não seria possível compatibilizar o máximo benefício do sombreamento, em relação ao teor proteico do pasto, com a máxima taxa de acúmulo de forragem. No presente trabalho, com o sistema estabelecido em área declivosa, em faixas no sentido norte/sul, e com árvores cujas alturas variavam entre 14 e $22 \mathrm{~m}$, as condições de sombreamento superiores a $30 \%$, incidentes a até $6 \mathrm{~m}$ de distância do renque de árvores, propiciaram maior teor proteico à forragem, mas foram prejudiciais ao perfilhamento e ao acúmulo de forragem. É possível obter benefícios do sombreamento moderado com os maiores acúmulos diários de forragem e de $\mathrm{PB}$, obtidos a 8,8 e 6,6 m de distância do renque de árvores, respectivamente.

Ao se levar em consideração que os renques de árvores estão dispostos consecutivamente na pastagem e que dois renques influenciam uma mesma faixa de pasto, deduz-se que os renques de árvores poderiam ser dispostos em espaçamentos que variam entre 14 e $18 \mathrm{~m}$, em vez de $30 \mathrm{~m}$, por causa das maiores taxas de acúmulo de $\mathrm{PB}$ e de MS estimadas a, aproximadamente, 7 e $9 \mathrm{~m}$ de distância de um dos renques, respectivamente. O estreitamento da faixa de pasto possibilitaria o aumento do número de árvores e, consequentemente, a maior produção de madeira e o melhor aproveitamento do efeito benéfico da sombra moderada sobre o acúmulo de forragem.

\section{Conclusões}

1. Em sistema agrossilvipastoril, há influência do componente arbóreo sobre a maioria das características do pasto, conforme o seu distanciamento ao renque de árvores.

2. A região do pasto, localizada entre 7 e $10 \mathrm{~m}$ de distância do renque arborizado, é onde ocorre melhor aproveitamento dos efeitos benéficos da sombra moderada sobre a densidade de perfilhos, a massa de forragem e os acúmulos de matéria seca e de proteína bruta.

3. O teor proteico do pasto é maior sob a copa das árvores e atinge o menor valor a $13,5 \mathrm{~m}$ de distância do renque de árvores; os teores de FDN não são afetados pelas árvores, e os de FDA e lignina não apresentam padrão de resposta definido em função do distanciamento da faixa arborizada.

\section{Agradecimentos}

À Fundação de Amparo à Pesquisa do Estado de Minas Gerais, pelo apoio financeiro.

\section{Referências}

ALLARD, G.; NELSON, C.J.; PALLARDY, S.G. Shade effects on growth of tall fescue: I. leaf anatomy and dry matter partitioning. Crop Science, v.31, p.163-167, 1991

AROEIRA, L.J.M.; PACIULLO, D.S.C.; LOPES, F.C.F.; MORENZ, M.J.F.; SALIBA, E.S.; SILVA, J.J. da; DUCATTI, C. Disponibilidade, composição bromatológica e consumo de matéria seca em pastagem consorciada de Urochloa decumbens com Stylosanthes guianensis. Pesquisa Agropecuária Brasileira, v.40, p.413-418, 2005.

BARUCH, Z.; GUENNI, O. Irradiance and defoliation effects in three species of the forage grass Brachiaria. Tropical Grasslands, v.41, p.269-276, 2007.

BUERGLER, A.L.; FIKE, J.H.; BURGER, J.A.; FELDHAKE, C.M.; MCKANNA, TEUTSCH, C.D. Forage nutritive value in an emulated silvopasture. Agronomy Journal, v.98, 1265-1273, 2006.

CARVALHO, M.M. de; SILVA, J.L.O. da; CAMPOS JUNIOR, B. de A. Produção de matéria seca e composição mineral da forragem de seis gramíneas tropicais estabelecidas em um sub-bosque de angico-vermelho. Revista Brasileira de Zootecnia, v.26, p.213-218, 1997.

CASTRO, C.R.T. de; GARCIA, R.; CARVALHO, M.M.; COUTO, L. Produção forrageira de gramíneas cultivadas sob luminosidade reduzida. Revista Brasileira de Zootecnia, v.28, p.919-927, 1999.

DIAS, P.F.; SOUTO, S.M.; RESENDE, A.S.; URGUIAGA, S.; ROCHA, G.P.; MOREIRA, J.F.; FRANCO, A.A. Transferência do $\mathrm{N}$ fixado por leguminosas arbóreas para o capim Survenola crescido em consórcio. Ciência Rural, v.37, p.352-356, 2007.

DIAS-FILHO, M.B. Growth and biomass allocation of the $\mathrm{C}_{4}$ grasses Brachiaria brizantha and B. humidicola under shade. Pesquisa Agropecuária Brasileira, v.35, p.2335-2341, 2000.

GAUTIER, H.; VARLET-GRANCHER, C.; HAZARD, L. Tillering responses to the light environment and to defoliation in populations of perennial ryegrass (Lolium perenne L.) selected for contrasting leaf length. Annals of Botany, v.83, p.423-429, 1999.

GUENNI, O.; SEITER, S.; FIGUEROA, R. Growth responses of three Brachiaria species to light intensity and nitrogen supply. Tropical Grasslands, v.42, p.75-87, 2008.

KALLENBACH, R.L.; KERLEY, R.L.; BISHOP-HURLEY, G.J. Cumulative forage production, forage quality and livestock performance from an annual ryegrass and cereal rye mixture in a Pine-Walnut silvopasture. Agroforestry Systems, v.66, p.43-53, 2006.

KEPHART, K.D.; BUXTON, D.R. Forage quality responses of C3 and C4 perennial grasses to shade. Crop Science, v.33, p.831-837, 1993. 
LIN, C.H.; MCGRAW, M.L.; GEORGE, M.F.; GARRET, H.E. Nutritive quality and morphological development under partial shade of some forage species with agroforestry potential. Agroforestry Systems, v.53, p.269-281, 2001.

OLIVEIRA, T.K. de; MACEDO, R.L.G.; SANTOS, I.P.A. dos; HIGASHIKAWA, E.M.; VENTURIN, N. Produtividade de Brachiaria brizantha (Hochst. ex A. Rich.) Stapf cv. Marandu sob diferentes arranjos estruturais de sistema agrossilvipastoril com eucalipto. Ciência e Agrotecnologia, v.31, p.748-757, 2007.

PACIULLO, D.S.C.; CAMPOS, N.R.; GOMIDE, C.A.M., CASTRO, C.R; TAVELA, R.C.; ROSSIELLO, R.O.P. Crescimento de capim-braquiária influenciado pelo grau de sombreamento e pela estação do ano. Pesquisa Agropecuária Brasileira, v.43, p.917-923, 2008.

PACIULLO, D.S.C.; CARVALHO, C.A.B. de; AROEIRA, L.J.M.; MORENZ, M.J.F.; LOPES, F.C.F; ROSSIELLO, R.O.P. Morfofisiologia e valor nutritivo do capim-braquiária sob sombreamento natural e a sol pleno. Pesquisa Agropecuária Brasileira, v.42, p.573-579, 2007.

PACIULLO, D.S.C.; LOPES, F.C.F.; MALAQUIAS JUNIOR, J.D.; VIANA FILHO, A.; RODRIGUEZ, N.M.; MORENZ, M.J.F.; AROEIRA, L.J.M. Características do pasto e desempenho de novilhas em sistema silvipastoril e pastagem de braquiária em monocultivo. Pesquisa Agropecuária Brasileira, v.44, p.1528-1535, 2009.

ROZADOS-LORENZO, M.J.; GONZALEZ-HERNANDEZ, M.P.; SILVA-PANDO, F.J. Pasture production under different tree species and densities in an Atlantic silvopastoral system. Agroforestry Systems, v.70, p.53-62, 2007.
SILVA, J.S.; QUEIROZ, A.C. da. Análise de alimentos: métodos químicos e biológicos. 3. ed. Viçosa: UFV, 2002. 235p.

SOUSA, L.F. Brachiaria brizantha cv. Marandu em sistema silvipastoril e monocultivo. 2009. 166p. Tese (Doutorado) Universidade Federal de Minas Gerais, Belo Horizonte.

SOUSA, L.F.; MAURÍCIO, R.M.; GONÇALVES, L.C.; SALIBA, E.O.S.; MOREIRA, G.R. Produtividade e valor nutritivo da Brachiaria brizantha cv. Marandu em um sistema silvipastoril. Arquivo Brasileiro de Medicina Veterinária e Zootecnia, v.59, p.1029-1037, 2007.

SOUSA, L.F.; MAURÍCIO, R.M.; MOREIRA, G.R.; GONÇALVES, L.C.; BORGES, I.; PEREIRA, L.G.R. Nutritional evaluation of "Braquiarão" grass in association with "Aroeira" trees in a silvopastoral system. Agroforestry Systems, v.79, p.189-199, 2010.

WILSON, J.R. Influence of planting four tree species on the yield and soil water status of green panic pasture in subhumid south-east Queensland. Tropical Grassland, v.32, p.209-220, 1998.

WILSON, J.R. Shade-stimulated growth and nitrogen uptake by pasture grasses in a subtropical environment. Australian Journal of Agricultural Research, v.47, p.1075-1093, 1996.

XAVIER, D.F. Monitoramento do fluxo de nitrogênio em pastagens de Brachiaria decumbens em monocultura e em sistema silvipastoril. 2009. 105p. Tese (Doutorado) - Universidade Federal Rural do Rio de Janeiro, Seropédica.

YAMAMOTO, W.; DEWI, I.A.; IBRAHIM, M. Effects of silvopastoral areas on milk production at dual-purpose cattle farms at the semi-humid old agricultural frontier in central Nicaragua. Agricultural Systems, v.94, p.368-375, 2007.

Recebido em 28 de junho de 2010 e aprovado em 9 de agosto de 2011

Pesq. agropec. bras., Brasília, v.46, n.10, p.1176-1183, out. 2011 